\title{
SOCIO-DEMOGRAPHIC ASPECTS AFFECTING INDIVIDUAL STANCES TOWARDS ELECTRIC AND HYBRID VEHICLES IN THE CZECH REPUBLIC
}

\author{
Formánek, T., Tahal, R.
}

Tomáš Formánek / University of Economics, Prague, Faculty of Informatics and Statistics, Dept. of Econometrics, W. Churchill Sq. 4, 13067 Praha 3, Czech Republic. Email:formanek@vse.cz.

Radek Tahal / University of Economics, Prague, Faculty of Business Administration, Dept. of Marketing, W. Churchill Sq. 4, 13067 Praha 3, Czech Republic. Email: radek.tahal@vse.cz.

\begin{abstract}
The world's human population and its natural environment are currently facing many unfavourable effects from climate change. A significant proportion of this phenomenon is attributable to air pollution generated by combustion engines used in transportation (greenhouse gases, dust particles, etc.). Despite the inevitable need for decisive actions to reverse climate change, central authorities may face significant pushbacks when actually promoting or enforcing electric and hybrid-based mobility, if a wrong (ineffective) mix of restrictions and incentives is applied. Using primary data from the Czech Republic (surveyed in 2019), we use logistic regression and other means of quantitative analysis to provide detailed information on socio-demographic and lifestyle factors affecting individual stances towards different aspects involved with the upcoming transition towards clean personal transportation. In this paper, we focus on topics related to electric and hybrid vehicles. Based on our analysis, we provide actionable information to facilitate the complex process of turning combustion-based transportation into a sustainable feature of our modern society. We find important gender and age-related differences in opinions towards diverse aspects related to changes in personal mobility. Women and older individuals are significantly more in favour of environmentally responsible transportation means. Active car-drivers (individuals who perceive themselves as such) in lifestyle segmentation are distinctively less in favour of ecologically oriented changes - hence such individuals ought be the primary targets for marketing and educational activities (perhaps even state-sponsored) aimed to shift vehicle (mobility in general) procurements towards environmentally responsible choices.

Implications for Central European audience: Climate protection is a key subject embedded in multiple EU policies. In Central European countries, the forthcoming transitioning of individual mobility towards EVs and hybrids might be a bit more complicated as compared to "old" EU members: our purchasing power is weaker, our car markets are more price sensitive and they rely heavily on imported second-hand cars. Our insights may be used to alleviate possible complications and bottlenecks in the process of reducing environmental pollution produced by individual transportation.
\end{abstract}

Keywords: Czech Republic; electric cars; hybrid cars; public perception; socio-demographic analysis

JEL Classification: C25, D12, M31, Q57 


\section{Introduction}

Electromobility is a key factor to achieve sustainable transportation for future generations. Nowadays, internal combustion engines in cars (trucks, motorcycles, etc.) create roughly $25 \%$ of all greenhouse gases (GHG) emitted in Europe and road transport accounts for more than $70 \%$ of transport-related $\mathrm{CO}_{2}$ emissions (Coppola and Arsenio, 2015). While combustion engines have been the main source of modern mobility, their undesirable effects (GHG, dust, noise, etc.) along with climate change effects have led to a growing portion of the global population calling for radical changes in this field.

Over the last decade, different EU institutions have presented plans to reduce GHG emissions from transport, such as that proposed by the European Commission seeking a $60 \%$ reduction with respect to 1990 levels by 2050 (EC-European Commission, 2011). Recently, many EU members have declared they are aiming for carbon-neutrality by 2050 (EC-European Council, 2019).

Current European environmental policies are based on a mix of restrictions on combustionbased cars (increased taxes, stricter emission regulations, restricted access to city centres, etc.) and incentives towards electric vehicles (EVs) (exemptions on VAT/purchase taxes, exemption from highway tolls, free inner-city parking and use of bus lanes, state subsidies to infrastructure/chargers, etc.). However, even with such administrative tools at hand, acceptance of electric (hybrid) vehicles by citizens may be nonexistent and/or a very slow process. The analysis by Coppola \& Arsenio (2015) emphasizing the importance of socioeconomic and behavioural research that would address and analyse individual stances and preferences with regards to electric and hybrid cars (or sustainable transportation in general) might assist the central authorities and the automotive industry with customizing their sustainability efforts for greater success.

The concept of EVs and hybrid vehicles is not novel. Kirsh (2000) explains that EVs have been on the market since the early 1910s in the USA. In modern times, Toyota Prius hybrid cars have been on the market since 1997 and available world-wide since 2000. In spite of this, the general public has only just recently entered a paradigm shift in which EVs and hybrids are transitioning from marginalized oddities to promising high-technology products.

EVs are quiet, arguably (locally) emission-free and reduce dependency on petroleum imports. Hybrid cars (and plug-in hybrids) combine both classical combustion engines and EV technology, thereby acting as a useful transition point between the two types of vehicles. The current leaders in the production of EVs (Tesla) and hybrid cars (Toyota Motor Corporation) are indisputable, but it is worth noting that most of the world's largest car producers (Volkswagen Group, Ford Motor Company, etc.) are moving fast towards hybrid and fully electric models. Nevertheless, this study (and the underlying survey undertaken in the Czech Republic, January to April 2019) does not follow separate car brands. Rather, we focus on the general concept of EVs and hybrid cars and corresponding aspects of the forthcoming (r)evolution in personal mobility - overall, we analyse individual stances towards different aspects of EVs and hybrid cars. EVs and hybrid cars are favoured over other devices that may assist in the transition towards electro-mobility (e.g. electric scooters, electric public transport vehicles, etc.) due to the fact that the effects of mass transitioning from combustionbased cars towards EVs shall far exceed impacts from other types of transportation, particularly in terms of environmental benefits and manufacturing. 
The remainder of this paper is organized as follows: the next chapter provides a brief literature review. Chapter 2 addresses the research methodology used (research questions, data collection and validation, quantitative analysis methods) and chapter 3 provides the main research results, along with a detailed discussion and critical evaluation. An evaluation of limiting factors, future research implications, conclusions and the list of references finalize our contribution.

\section{Literature review}

The reduction of GHG emissions in transportation through EVs and hybrid cars has become a phenomenon of recent years of which is well reflected in scientific literature. Different authors and experts address specific topics of the rather complex electromobility phenomenon - EVs as the core product, battery chargers and related services, impact on corporate strategies, public infrastructure planning, etc. For example, Chovan \& Straka (2015) discuss how EVs and charging stations must be embraced by urban planning and city management. Similarly, Alochet \& Midler (2019) point out that public implementation strategies, necessary for EV-markets to scale up have been neglected so far.

Power grid management is one of the key areas - and perhaps bottlenecks - for the successful expansion of electromobility. Papadopoulos et al. (2012) discuss and evaluate how EV charging will increase energy demand and affect distribution networks. Salah \& Kama (2016) see the future of infrastructure and EV-charging in electricity distribution networks that use digital communications and Internet of things (IOT) to monitor and manage electricity consumption and distribution, otherwise known as smart grids. Smart grids allow for remote maintenance, predictive functionality features as well as "smart" pricing for users. For example, smart grids may be used to stabilize energy demand by financially discouraging peak hour charging of EVs.

Gebauer et al. (2016) point out that EV-related infrastructure (charging stations) is perceived as an important indicator by the general public in that it affects how people assess the general prospect of EVs. The economic aspect of electromobility is also important. Messagie et al. (2013) note the differences between EVs and combustion-engine cars; they point out how the purchase cost of EVs is mostly linked to battery capacity instead of vehicle size. Hence, in comparison to their respective combustion-based counterparts, small/city EVs tend to be relatively more expensive than premium EVs.

A lack of consistency in EV-related policies applied by different countries has been stressed by numerous others. Bobeth \& Matthies (2016) emphasize the impact of government incentives on EV-sales, giving the examples of car markets in Norway and Germany. While Norway's active, environmentally responsible policies are fuelling an electric-car boom, Germany is lagging heavily. Begley et al. (2016) point out the heterogeneous nature of policies implemented by different states, despite the similarities in ambitions: reduction of GHG emissions and transformation from conventional transport technologies to greener alternatives. Nevertheless, in spite of these differences, Cansino et al. (2018) point out that higher penetration levels of EVs and hybrid cars appear in countries where the car registration tax and ownership tax (or both) have developed into a partially "green tax" that includes GHG emissions in the calculation of total tax rates. Furthermore, Yan et al. (2017) provide evidence that stricter environmental regulation leads to increased research \& development and implementation of cleaner technologies. 


\section{Research methodology and data}

\subsection{Research focus}

This article focuses on socio-demographic and lifestyle factors that influence individual stances towards EVs and hybrid cars and EV-related mobility factors in general. Major attention is devoted to gender and age-based differences. Besides socio-demographically determined differences, we also evaluate relevant socio-economic and lifestyle segmentation of the population. This approach corresponds with the methodology applied by Chung \& Hsu (2012), who emphasize the importance of quantified lifestyle factors for market segmentation and preparation of marketing strategies. Our research efforts may be summarized using the following topics/goals:

1. Identify socio-demographic and lifestyle-based differences in individual stances towards environmentally responsible changes in personal mobility.

2. Identify potential bottlenecks: groups of sceptics or individuals where marketing and educational activities would be most efficient as we aim to reduce the negative environmental impacts of personal mobility by increasing the share of EVs and hybrid vehicles.

\subsection{Data gathering \& handling}

Our quantitative research is based on primary data for the Czech Republic and we used the population aged 15 years and older (15+) for sampling. Data gathering took place during the period January to April 2019. In a stratified/quota sampling process, a total of 452 complete and properly filled survey forms were collected by means of personal data collection channels. Complex survey forms were used to collect anonymized data: respondent's sociodemographic data, lifestyle activities and general preferences in a wide range of work and leisure activities as well as stances towards important aspects concerning the upcoming changes in personal mobility. The survey featured open, closed and scaled types of questions. In most cases, Yes/No, Likert scale (5-degree spans) and interval-based quantitative queries were used. Table 1 provides detailed information regarding the structure of our sample and how the quota/sampling process matched the population sampled. From Table 1, we may see a good match between the population and sample structures - thus, the dataset ensures interpretability of the results with respect to the Czech population.

The survey was prepared and executed by researchers at the University of Economics, Prague. The research team was guided by university teachers who direct and oversee the work of students majoring in marketing research. The "Runs" test and similar data-validation procedures were used to test for potential survey mishandling (Gibbons \& Chakraborti, 2003). Under random sampling, quantitative analysis based on logistic regression was adjusted to control for stratified/quota sampling, thereby further ensuring interpretability of the results with respect to the population sampled. This study is part of a long-term project of systematic surveys and analyses focusing on consumer behaviour and individual stances towards new challenges presented by the rapid technological advances affecting our modern society (e.g. Formánek \& Tahal, 2016;Tahal, Formánek \& Mohelská, 2017). 
Table 1 | Czech population structure and the quota sampling used

\begin{tabular}{llcc}
\hline Category & Strata & $\begin{array}{c}\text { Population } \\
\text { Quota (\%) }\end{array}$ & $\begin{array}{c}\text { Sample } \\
\text { Respondents (\%) }\end{array}$ \\
\hline Gender & Male & 49 & 50 \\
\hline Age group & $15-24$ years & 51 & 50 \\
\hline $25-34$ years & 14 & 24 \\
& $35-49$ years & 17 & 17 \\
& $50-64$ years & 26 & 23 \\
& $65+$ years & 24 & 21 \\
Location & Prague & 19 & 15 \\
& Bohemia & 12 & 17 \\
& Moravia & 53 & 52 \\
\hline
\end{tabular}

Source: authors

To evaluate the socio-demographic and lifestyle factors influencing individual stances towards the upcoming changes in individual mobility induced by environmental considerations (with special focus on EVs and hybrids), we used the following six binary dependent variables, extracted from our surveyed data (shown in Table 2): variable (a) $E V \_L T \_F u t u r e$, equalling 1 for individuals who foresee $E V s$ as the main transport platform in the long-term future - beyond a 20-year horizon (as opposed to individuals who see EVs as complementary or non-existent in the long-term, for whom this variable equals zero); (b) Hybrid_MT_Future, equalling 1 for individuals who perceive hybrid cars (featuring both internal combustion and electric engines) as the predominant technology in the mid-term future - within a 20-year horizon. The first two categories come from different questions/time horizons and the corresponding answers are thus not mutually exclusive. Variable (c) $E V \_$Responsible, equalling 1 for individuals who perceive owners of electric vehicles as responsible towards the natural environment (highest rank on a 5-point Likert scale); (d) City_Regulation, describing individuals who are strongly in favour of restricting access for 'old' combustion vehicles to city centres with 50.000 or more inhabitants - technically, this question targets cars not fulfilling the Euro 5 norm (codified in EP-European Parliament, 2007); (e) Tried_EV, identifying individuals who report first-hand experience with EVs or hybrid cars, either as drivers or passengers. Finally, (f) EV_Prestige depicting individuals who perceive EV ownership as a prestige symbol. This variable originates from a different question than EV_Responsible and thus the responses are not mutually exclusive. The classification and selection of variables (a) to (f) was based on the authors' experience and practice from similar research activities because direct support in relevant literature is not yet available. We specifically aimed at selecting a heterogeneous (yet concise) set of variables that would provide complex information reflecting stances towards the upcoming changes in personal mobility from different angles (points of view) and with as little duplicities as possible. 
Table 2 | Basic features of the dependent/explained variables

\begin{tabular}{lccc}
\hline Variable & $\begin{array}{c}\text { Number of. } \\
\text { "successes" }\end{array}$ & Mean value & Variance \\
\hline (a) EV_LT_Future & 241 & 0.533 & 0.249 \\
(b) Hybrid_MT_Future & 194 & 0.429 & 0.246 \\
(c) EV_Responsible & 151 & 0.334 & 0.223 \\
(d) City_Regulation & 133 & 0.294 & 0.208 \\
(e) Tried_EV & 88 & 0.195 & 0.157 \\
(f) EV_Prestige & 82 & 0.181 & 0.149 \\
\hline
\end{tabular}

Source: authors

Upon close examination of the surveyed data, we found that individuals in the Czech Republic are generally unaware of the fact that most EV charging tasks are performed overnight (i.e. at home) in a "slow-mode". Hence, a corresponding question addressing the perceived availability/coverage of EV-charging stations ("fast-chargers") was removed from further consideration for this article.

From Table 2, we may see that topics (a) to (f) are organized in descending order by their "success" ratios, i.e. by the number of observed positive answers. Results of the Wilcoxon signed rank tests for "matched pairs" (for details, see Gibbons and Chakraborti, 2003) show that mean values for categories (c) and (d) are not statistically different at the $5 \%$ significance level. The same finding applies to categories (e) and (f). Information on variance is provided mainly for readers' convenience: for binomial $\{0,1\}$ variables, variance always equals $p(1-$ $p$ ) where $p$ is the mean value. Data shown in Tables 1 and 2 provide general information on the survey performed and the main "response" variables. In order to identify statistically significant socio-demographic and lifestyle-based contrasting factors affecting individual stances towards environmentally responsible personal transportation, we used logistic regression, as described in the next section.

\subsection{Quantitative methods}

From Table 2, we may see how similar or dissimilar are the general propensities to individual identification with positions towards selected EV-related issues. However, this does not mean that identical/similar positive outcome ratios (mean values) are generated by identical/similar respondent groups (statistically speaking). Theoretically, positive outcomes in the (c) and (d) categories may result from two mutually exclusive groups, that is those with no apparent common factors. While different random influences play a significant role at the individual level, by means of logistic regression we can often identify and quantify statistically significant socio-demographic and lifestyle-based differences in individual opinions.

From the 452-row (observations) and 140-column (variable) dataset that was assembled using the surveyed data, we selected the six dependent variables described in the previous section and given in Table 2 and a total of 99 potential explanatory variables featuring sociodemographic, lifestyle and other relevant information provided by the respondents. To address our research questions, we applied a robust algorithm to select a parsimonious, yet representative and informative set of explanatory variables for our logistic model. We 
combined forward-stepwise selection methods (a potentially suboptimal algorithm generating sequences of nested models) with the non-parametric random forest approach to the evaluation of the importance of various regressors (Hastie et al., 2001). In combining the methods, we were able to detect any potential sub-optimality in the stepwise algorithm and evaluate the relative importance of each explanatory variable with respect to prediction accuracy, all the while ensuring computational feasibility.

We note that the exhaustive (brute-force) search for a true optimum specification for equation (1) is computationally inaccessible as it would require an estimation and evaluation of a total of $6 \times 2^{99}$ models while the stepwise algorithm only requires the evaluation of some $6 \times 99^{2}$ models and we used 5.000 trees for each of the six random forests evaluated. Although the approach chosen does not ensure the best model setup possible, it is an acceptable approximation with only a small potential for sub-optimality.

$$
\begin{aligned}
& y_{i}=\beta_{0}+\beta_{1} \text { Female }_{i}+\beta_{2} \text { Age25_34 } i+\beta_{3} \text { Age35_49 } i+\beta_{4} \text { Age50_64 } i+ \\
& +\beta_{5} \text { Age65Plus }_{i}+\beta_{6} \text { Prague }_{i}+\beta_{7} \text { Earnings_high }_{i}+\beta_{8} \text { LS_books }_{i}+ \\
& +\beta_{9} \text { LSgreenFing }_{i}+\beta_{10} \text { LSactiveDriver }_{i}+\beta_{11} \text { LSpremCloths }_{i}+
\end{aligned}
$$

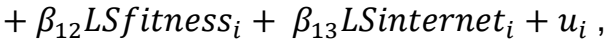

In equation (1) $y_{i}$ is a binary dependent variable (for analysis consistency, the same model specification is used for each of the six variables introduced in Table 2). Female $_{i}$ describes respondents' gender (equals 1 for women, 0 otherwise). The next four variables are used to describe interval-based information on respondent's age: $A g e 25_{-} 34_{i}$ equals 1 if the $i$-th individual is 25 to 34 years old and it equals 0 otherwise. The corresponding interpretation of Age35_49 ${ }_{i}$ and $A g e 50 \_64_{i}$ variables is straight-forward and Age65Plus $_{i}$ covers all individuals aged 65 and more. We note that the age category 15 to 24 years is omitted from equation (1) for technical reasons and serves as a reference age level for interpretation purposes (Greene, 2018). Similarly, Prague $_{i}$ is a binary variable used to identify respondents with a residence in Prague and Earnings_high $h_{i}$ identifies individuals with a total monthly household income of CZK 80.000 or more (approx. EUR 3.100+). The surveyed information on education levels achieved is left out of equation (1) as it does not provide any statistically significant contrasting factors to the logistic regression function.

The remaining variables of equation (1) are lifestyle-based binary indicators drawn from Likert scale questions. For example, respondents were presented with a statement "I like reading books." and asked to position themselves towards this statement using a 5-degree Likert scale (" 1 " = this statement describes me very well", " 5 " = this statement doesn't describe me at all). Subjective perception of respondents' preference/lifestyle is expressed here, rather than the actual time spent doing the activity or the number of pages read. LSgreenFings equals 1 for individuals who strongly associate themselves with the hobby of gardening (growing fruits/vegetables, lawn mowing, etc.) and zero otherwise. Similarly, the variables

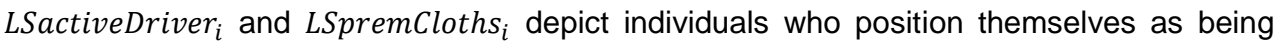
active drivers and preferring a premium-brand clothing, respectively. LSfitness $s_{i}$ separates individuals who identify themselves as participating in sports/fitness/gym activities (equals 1 for such individuals, zero otherwise). LSinternet $t_{i}$ marks individuals who associate themselves with a strong on-line presence (again, subjectively perceived importance is 
addressed here rather than time spent, bandwidth used, etc.). Parameters $\beta_{j}$ are coefficients of the model to be estimated and $u_{i}$ is the usual random element (potentially heteroskedastic).

For the sake of completeness, it should be stated that, for all lifestyle activities surveyed, dummy variables describing individuals who strongly dissociate themselves from such activities were also constructed. However, those were not included into equation (1) due to their general lack of statistical significance in the model.

The $\beta_{j}$ coefficients of equation (1) are estimated using the logistic function:

$$
\mathrm{P}\left(y_{i}=1 \mid \boldsymbol{x}_{i}^{T}\right)=\Lambda\left(\boldsymbol{x}_{i}^{T} \boldsymbol{\beta}\right)=\exp \left(\boldsymbol{x}_{i}^{T} \boldsymbol{\beta}\right) /\left[1+\exp \left(\boldsymbol{x}_{i}^{T} \boldsymbol{\beta}\right)\right],
$$

where $\mathrm{P}\left(y_{i}=1 \mid \boldsymbol{x}_{i}^{T}\right)$ is the probability of individual identification with EV-related stances as described by the variables in Table 2 , given the observed individual set of explanatory variables. Expression $\boldsymbol{x}_{i}^{T} \boldsymbol{\beta}$ is a vector-form representation of the right-hand side of equation (1), excluding the random element. The nonlinear nature of the logistic function $\Lambda\left(\boldsymbol{x}_{i}^{T} \boldsymbol{\beta}\right)$ ensures that all fitted probabilities lie within the probabilistic $\langle 0,1\rangle$ interval. Parameters $\beta_{j}$ are estimated using the maximum likelihood method (Greene, 2018). Given the non-linear nature of $\Lambda\left(\boldsymbol{x}_{i}^{T} \boldsymbol{\beta}\right)$, interpretation possibilities for the estimated $\beta_{j}$ coefficients are very limited.

Using equation (2), the expected effect of a change in a given regressor $x_{j}$ on the probability of "success" $\mathrm{P}\left(y_{i}=1 \mid \boldsymbol{x}_{i}^{T}\right)$ can be calculated for each $i$-th individual. Despite the relative numerical complexity of such a calculation, this type of analysis is widely used in statistic/econometric software packages, as individual information can be summarized across the whole sample into a well-established summary statistic through the process of averaging changes in expected probabilities, a point captured in the average partial effect (APE). Estimated APEs are usually reported along with their corresponding standard errors and significance statistics ( $p$-values).

While all regressors in equation (1) are binary, our techniques provide sufficient control over a broad range of observed influencing factors. This allows for a direct (ceteris paribus) interpretation of individual factors, assuming ignorability (Wooldridge, 2010, p. 908).

\section{Results and discussion}

Our analysis and the corresponding discussion may start with Table 2 - the variables included, and their ordering, provide a general summary of individual attitudes. Table 2 shows the observed ratios of personal stances (opinions) related to different aspects of the ongoing progress towards EV-based mobility. While $53.3 \%$ of individuals see EVs as the long-term successor to the combustion engines, only $29.4 \%$ agree with immediately applicable restrictions on the use of traditional combustion vehicles (specifically, banning cars not compliant with the Euro 5 norm from city centres).

While the information provided in Table 2 provides some basic insight into sustainable mobility, additional layers of analysis are necessary to generate a complex insight into the socio-demographic and lifestyle determinants of individual positions towards sustainable mobility. Hopefully, such analysis will provide actionable information to facilitate the transition of personal mobility towards clean (cleaner) technologies, represented by EVs and hybrid vehicles. 
Empirically, similar outcomes as surveyed for two distinct questions (e.g. (b) Hybrid_MT_Future and (c) EV_Responsible) in Table 2 may come from two very distinct groups of individuals, perhaps even mutually exclusive. This observation is noted with the point that multiple random influences play a significant role in defining respondent's individual opinions and stances. However, using logistic regression, we are often able to identify and quantify statistically significant differences in opinions/perceptions across diverse sociodemographic and other defined groups of individuals.

Table 3 provides this type of detailed analysis: it is based on the regression model (1), estimated for each of the 6 binary dependent variables (from Table 2). Columns in Table 3 follow from question-ordering (a) to (f) used in Table 2. All six estimated logistic models are statistically significant and provide sound interpretation accuracy. As the estimated regression coefficients $\beta_{j}$ of the logistic models (1) are not very informative (except for their signs and statistical significances), we skip raw regression output and show the corresponding APE values. All the omitted estimations are available from the authors upon request, along with raw data, supplementary plots and $\mathrm{R}$-software codes used for estimation.

From Table 3, we may see that women are more positively inclined towards the transition from combustion-based to clean(er) mobility: Compared to men (reference category), female respondents are $13.5 \%$ more likely to see hybrid vehicles as the mid-term ascendant technology and they are $13.1 \%$ more likely to see EVs as environmentally responsible. This interpretation holds at the $5 \%$ significance level and is based on a ceteris paribus basis - i.e. it holds for any given factor, explicitly included in model (1): age, domicile, lifestyle preferences, etc. 
Table 3 | Estimated APEs with corresponding standard errors and $p$-values

\begin{tabular}{|c|c|c|c|c|c|c|}
\hline Variable & $\begin{array}{l}\text { EV_LT } \\
\text { _Future }\end{array}$ & $\begin{array}{c}\text { Hybrid_MT } \\
\text { _Future }\end{array}$ & $\begin{array}{c}E V \_R e s p o n \\
\text { sible }\end{array}$ & $\begin{array}{c}\text { City_Regul } \\
\text { ation }\end{array}$ & Tried_EV & $\begin{array}{c}E V \_ \text {Prestig } \\
e\end{array}$ \\
\hline Female & -0.0497 & 0.1351 & 0.1314 & 0.0889 & -0.1530 & 0.0109 \\
\hline ( st. error ) & $(0.0488)$ & $(0.0492)$ & $(0.0443)$ & $(0.0460)$ & $(0.0369)$ & $(0.0382)$ \\
\hline [ $p$-value ] & [ 0.3093 ] & {$[0.0060]$} & [0.0030 ] & {$[0.0535]$} & {$[0.0000]$} & [ 0.7743 ] \\
\hline \multirow[t]{3}{*}{ Age25_34 } & -0.0258 & -0.0689 & 0.0530 & 0.1435 & -0.0040 & 0.0496 \\
\hline & $(0.0675)$ & $(0.0629)$ & $(0.0656)$ & $(0.0677)$ & $(0.0476)$ & $(0.0600)$ \\
\hline & [ 0.7028 ] & [ 0.2737 ] & [ 0.4193 ] & {$[0.0341]$} & [ 0.9331$]$ & [ 0.4088 ] \\
\hline \multirow[t]{3}{*}{ Age35_49 } & -0.1666 & 0.0373 & 0.1972 & 0.1791 & -0.0256 & 0.1055 \\
\hline & $(0.0700)$ & ( 0.0695$)$ & ( 0.0699$)$ & $(0.0744)$ & $(0.0484)$ & $(0.0687)$ \\
\hline & {$[0.0173]$} & [ 0.5922 ] & [ 0.0048$]$ & {$[0.0160]$} & [ 0.5962 ] & {$[0.1251]$} \\
\hline \multirow[t]{3}{*}{ Age50_64 } & -0.2024 & 0.0069 & 0.0272 & 0.1505 & -0.0055 & -0.0390 \\
\hline & $(0.0674)$ & $(0.0723)$ & $(0.0658)$ & $(0.0715)$ & $(0.0526)$ & $(0.0554)$ \\
\hline & [ 0.0027 ] & [ 0.9238 ] & [ 0.6798 ] & {$[0.0352]$} & [ 0.9166 ] & [ 0.4817$]$ \\
\hline \multirow[t]{3}{*}{ Age65+ } & -0.2495 & 0.0330 & 0.2324 & 0.2864 & -0.0624 & 0.2998 \\
\hline & $(0.0826)$ & $(0.0967)$ & $(0.0891)$ & $(0.0913)$ & $(0.0593)$ & $(0.1061)$ \\
\hline & {$[0.0025$ ] } & {$[0.7325]$} & {$[0.0091]$} & {$[0.0017]$} & [ 0.2924 ] & [ 0.0047$]$ \\
\hline \multirow[t]{3}{*}{ Prague } & 0.0386 & 0.0236 & -0.1155 & 0.0474 & 0.1297 & -0.0915 \\
\hline & $(0.0543)$ & $(0.0541)$ & $(0.0454)$ & $(0.0482)$ & $(0.0455)$ & $(0.0371)$ \\
\hline & {$[0.4767$ ] } & [ 0.6624 ] & {$[0.0110]$} & {$[0.3261]$} & [ 0.0044 ] & [ 0.0137 ] \\
\hline \multirow{3}{*}{$\begin{array}{c}\text { Earnings } \\
\text { _high }\end{array}$} & -0.0077 & -0.0447 & 0.0152 & -0.0007 & 0.1611 & -0.0328 \\
\hline & $(0.0842)$ & $(0.0808)$ & $(0.0791)$ & $(0.0804)$ & $(0.0702)$ & $(0.0600)$ \\
\hline & [ 0.9273 ] & {$[0.5800]$} & [ 0.8478 ] & [ 0.9931$]$ & [ 0.0218 ] & [ 0.5844 ] \\
\hline \multirow[t]{3}{*}{ LS_books } & 0.0121 & 0.0903 & 0.0516 & 0.0103 & 0.0148 & 0.0376 \\
\hline & $(0.0487)$ & $(0.0482)$ & $(0.0453)$ & $(0.0460)$ & $(0.0373)$ & $(0.0375)$ \\
\hline & {$[0.8036$ ] } & [0.0609 ] & [ 0.2550 ] & {$[0.8228]$} & [ 0.6928 ] & [ 0.3156 ] \\
\hline LSgreen & 0.0737 & -0.0454 & 0.1124 & 0.1192 & -0.1267 & 0.0066 \\
\hline \multirow[t]{2}{*}{ Fings } & $(0.0550)$ & $(0.0543)$ & $(0.0526)$ & $(0.0527)$ & $(0.0368)$ & $(0.0413)$ \\
\hline & {$[0.1801]$} & {$[0.4031]$} & [ 0.0327 ] & [ 0.0239 ] & {$[0.0006$ ] } & [ 0.8722 ] \\
\hline & -0.0261 & 0.0745 & -0.1417 & -0.1050 & 0.1060 & -0.0077 \\
\hline \multirow[t]{2}{*}{ Driver } & $(0.0530)$ & $(0.0527)$ & $(0.0504)$ & $(0.0510)$ & $(0.0367)$ & $(0.0442)$ \\
\hline & [ 0.6223 ] & {$[0.1571]$} & {$[0.0050]$} & [0.0395 ] & [ 0.0039 ] & {$[0.8616$ ] } \\
\hline LSprem & -0.0365 & 0.0663 & 0.2316 & 0.0339 & -0.0561 & -0.0103 \\
\hline \multirow[t]{2}{*}{ Cloths } & $(0.0766)$ & $(0.0779)$ & $(0.0767)$ & $(0.0712)$ & $(0.0449)$ & $(0.0586)$ \\
\hline & [ 0.6331$]$ & [0.3943 ] & {$[0.0025]$} & [ 0.6337 ] & [ 0.2116 ] & [ 0.8611$]$ \\
\hline \multirow[t]{3}{*}{ LSfitness } & 0.0945 & -0.0404 & 0.0671 & 0.0627 & 0.1138 & 0.0096 \\
\hline & $(0.0557)$ & $(0.0539)$ & $(0.0528)$ & $(0.0538)$ & $(0.0470)$ & $(0.0449)$ \\
\hline & [ 0.0899 ] & [ 0.4539$]$ & {$[0.2041]$} & {$[0.2445]$} & [ 0.0155 ] & [ 0.8308 ] \\
\hline \multirow[t]{3}{*}{ LSinternet } & 0.0295 & 0.1362 & 0.0184 & 0.1189 & -0.0030 & 0.0521 \\
\hline & $(0.0741)$ & $(0.0692)$ & $(0.0652)$ & $(0.0587)$ & $(0.0571)$ & $(0.0531)$ \\
\hline & [ 0.6907 ] & {$[0.0490]$} & [ 0.7783 ] & {$[0.0429]$} & {$[0.9576$ ] } & [ 0.3265 ] \\
\hline
\end{tabular}

Source: authors

Female respondents are also $8.9 \%$ more likely to agree with city regulations - question (d) targeting vehicles propelled by internal combustion; however, this result marginally misses the $5 \%$ significance level (with $p$-value of 0.053 ). Interestingly, female respondents are $15.3 \%$ less likely to have previous experience with EVs - question (e); again, this result holds ceteris paribus, i.e. given age classification, lifestyle preferences (e.g. being active driver or not), etc. 
For questions (a) and (f), there are no differences between stances of male and female respondents.

The description of age-based differences in attitudes towards clean personal transportation is more complicated. There are 5 age groups/intervals used to describe respondent's age (four categories included explicitly in our model, plus the 15-24 year reference group) and the interpretations of different APEs (and their statistical significances) are only valid with respect to the base group (age 15-24). To highlight some of the most important findings shown in Table 3, we can see that identification with EVs being the long-term future of mobility - question (a) - decreases relatively steeply with increasing age. In comparison, city regulations - question (d) - are perceived increasingly favourably in higher age groups (with respect to the reference). We observe no significant age-based differences in questions (b) and (e), hybrids seen as the mid-term future and having personal experience with EVs, respectively. Interestingly, the oldest respondents (65 and older) exhibit distinctively more positive attitudes towards two connotations related to EV-ownership: EVs being perceived as responsible and prestigious - questions (c) and (f); acceptance of this position is $23.2 \%$ and $30 \%$ higher than in the reference group (age 15-24).

To provide a more complete and unambiguous description of all the gender and age-based effects, Figure 1 is included (underlying calculations are based on the methodology described by Fox \& Hong, 2009). Figure 1 is produced using the estimated model (1) and it shows the probabilities of individual's agreement with statements/questions (a) to (f) as in Table 2. Estimated 95\% significance intervals are shown and may be used to assess the statistical significances of gender-based and age-based differences. To preserve adequate interpretation, factors not shown in Figure 1 (domicile, lifestyle-based variables, etc.) are fixed at representative values (for detailed discussion, see Fox \& Hong, 2009). The interpretation of data shown in Figure 1 is straight-forward. For example, city regulation approval - question (d) - is about $20 \%$ for the youngest female age group (15-24 years) and it rises relatively steadily to approximately $60 \%$ for females aged 65 and more. Similarly, readers can see how males are more likely to have previous personal experience with EVs (with negligible agebased differences for both genders) and how perceiving EVs as the long term future of personal mobility - question (a) - decreases from 65\% (approximately, both genders) for the youngest group to $50 \%$ (women) and $30 \%$ (men) for oldest individuals.

As we continue to discuss the results presented in Table 3, we can see that individuals domiciled in Prague (capital city) are about 13\% more likely to have previous experience with EVs when compared to the rest of the country. Similarly, high-earning individuals are $16.1 \%$ more likely to report EV-experience as opposed to the rest of respondents. 
Figure 1 | Summary of gender and age-based effects on EV-related opinions (95\% confidence intervals included)

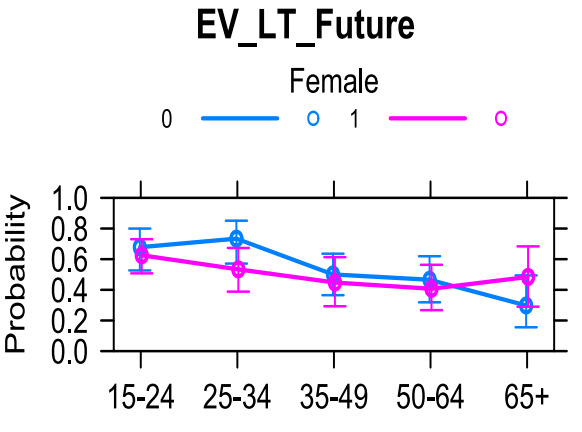

Age_code
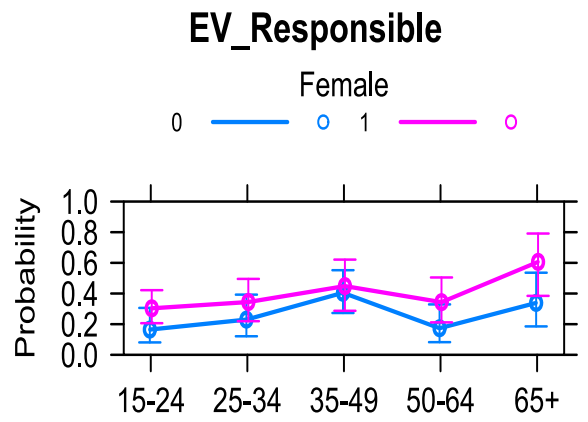

Age_code

\section{Tried_EV}

Female

0

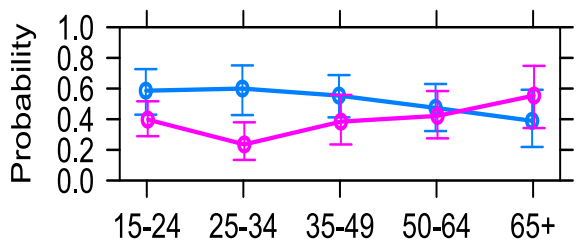

Age_code
Hybrid_MT_Future

Female

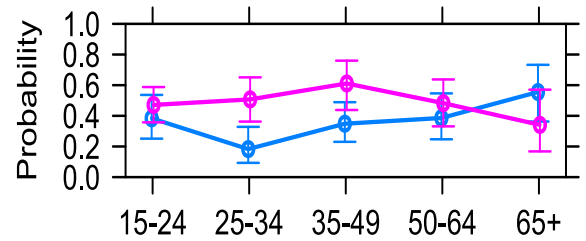

Age_code

City_Regulation

Female
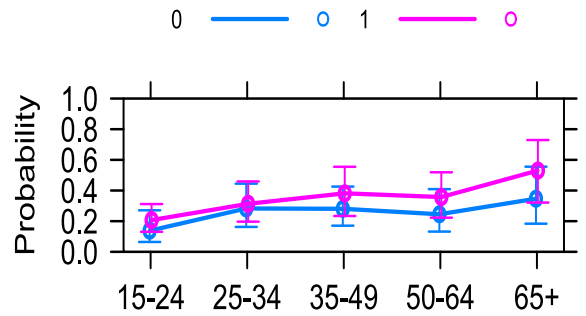

Age_code

\section{EV_prestige}

Female

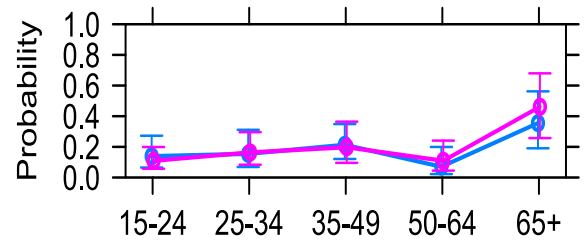

Age_code

Source: authors

By turning our attention to the lifestyle factors selected as regressors for model (1), we may see how their effects on dependent variables - questions/categories (a) to (f) in Table 2 - are more selective (compared to the influences incurred by gender, age, etc.). However, lifestylebased variables provide interesting context as well as enhanced/robust ceteris paribus interpretation to the previously discussed socio-demographic elements. For example, individuals engaging in hobby-gardening and other related activities (variable LSgreenFings) 
seem to exhibit stronger environmental awareness and self-constraint: they are $11.9 \%$ more likely to agree with city regulations imposed on combustion-based vehicles and $11.2 \%$ more likely to perceive EV ownership as a sign of responsibility towards the environment. At the same time, individuals keen on gardening are $12.6 \%$ less likely to have previous EV experience; using the same reasoning, we may explain the lack of effects of this lifestyle factor on questions (a) and (b): hobby gardeners and other individuals with "green fingers" are unlikely to closely follow advances in EVs and hybrid cars and therefore tend not to have strong opinions on the technological aspects and developments of personal mobility in the long-term and mid-term.

Habitual book readers and internet users (variables LS_books and LSinternet) are more inclined to see hybrid vehicles as the mid-term future of personal mobility - question (b) with $9 \%$ and $13.6 \%$ increase in probability, respectively. Individuals with strong brandawareness (variable LSpremCloths may be viewed as a proxy for brand-awareness) reflect on EVs as a responsible "technology" by $23.2 \%$ more than the corresponding reference group. Interestingly, physically active individuals (variable LS fitness) are $11.4 \%$ more likely to have previous EV experience (ceteris paribus) as well as $9.5 \%$ more likely to see EVs as the long term future of personal mobility (however, this last result is only significant at $\alpha=$ $0.1)$.

The attitudes expressed by active drivers (variable LSactiveDriver) deserve a detailed discussion. Given their driving-related activities and interests, such individuals are $10.6 \%$ more likely to have previous experience with EVs. At the same time, they are $10.5 \%$ less likely to agree with city regulations - question $(d)$ - which is only logical as it would tend to limit their current driving-related activities. Interestingly, active drivers are $14.2 \%$ less likely to apprehend EVs as environmentally responsible and there is no statistical difference between active drivers and the reference group with respect to perceived mid-term and long-term technological prospects - questions (a) and (b). Again, please recall the ceteris paribus interpretation of the calculated APES (i.e. interpretation for any given age, gender and lifestyle group member). Overall, any marketing, advertising, educational and environmental awareness enhancing activities should be focused towards active drivers.

\section{Limitations and future research}

Marketing activities involving new and disruptive high-technology products may be severely complicated by a lack of relevant market data. Beard \& Easingwood (1996) show that for revolutionary innovations, marketers tend to emphasize the technological component of their products and focus more on positioning and market penetration rather than on market preparation, segmentation and targeting. This article provides a useful insight as it clearly aims at supporting the latter (and often overlooked) part of marketing activities related to EVs and hybrids.

However, general perception towards EVs and hybrid vehicles may be changing rapidly. As an increasing number of clean vehicles are being sold and used, new individuals from the general public are exposed to their presence, thus gaining more insight and sounder stances on the topic of EVs and hybrid vehicles overall. From an EV-focused study covering rural areas of Norway (Kester et al., 2019), it can be seen how individual acquaintance (not necessarily a first-hand experience) is essential for establishing favourable public perceptions. In the Czech Republic, sound individual acquaintance with EVs and hybrid 
vehicles is partly missing and partly evolving rapidly. Hence, it would be highly advisable to repeat the survey and this type of research in the near future - say two to three times over the next five years or so. This way, we can improve the knowledge of public stances and thus facilitate the ultimate goal of decarbonizing individual (and general) transportation.

Future research in this field may focus on a range of technical and practical aspects of green and environmentally responsible personal mobility. So far, topics such as availability of fast-charging facilities for EVs and car sharing schemes defy representative quantitative analysis in the Czech Republic: only the most technologically savvy individuals are reasonably knowledgeable for competent evaluation. For example, we found out that respondents in the Czech Republic are generally unaware of the fact that most of EV charging tasks are performed overnight (i.e. at home) in a "slow-mode". Hence, the research as presented in this article - which covers key general aspects of the personal mobility transformation process - may be refined and improved as corresponding technology becomes more wide-spread and better understood by consumers.

\section{Conclusions}

Today's marketing professionals actively search for innovative ways of attracting customers to greener and more environmentally responsible technologies. This transition is mostly driven by restrictions imposed on GHG and other pollutants by state authorities and international treaties, yet consumers' environmental awareness and purely economic motives play a role as well. While this transformation is replicated in many industrial, retail and services segments, it is markedly prominent in the field of car sales and - more generally in the personal mobility sector.

In this article, we categorize and describe different socio-demographic and lifestyle consumer groups with respect to their stances towards various aspects of environmentally responsible personal mobility. Adequate quantitative analysis and appropriately adjusted marketing and educational efforts can bring forward both financially and environmentally advantageous effects when compared with traditional approaches. The identified similarities and distinctive properties of consumer attitudes may be used by car manufacturers and central authorities alike to promote green procurement in the automotive sector.

From the socio-demographic perspective, we find many aspects where women and individuals belonging to older age groups are notably more inclined towards changes incurred in greener means of personal transportation. By analysing multiple lifestyle-based groups, we can see that "active drivers" (individuals self-positioning themselves as such) seem to strongly prefer traditional (combustion-based) vehicles and they are also more likely to oppose city regulations aimed against highly polluting old vehicles/engines.

\section{Acknowledgement}

This work is supported through grant IGA F4/19/2019 from the Faculty of Informatics and Statistics, University of Economics, Prague. 


\section{References}

Alochet, M. \& Midler, C. (2019). Reorienting electric mobility research focus on industrialisation issues. International Journal of Automotive Technology and Management, 19(3-4), 29-256. https://doi.org/10.1504/ijatm.2019.100915.

Beard, C \& Easingwood, C. (1996). New product launch: Marketing action and launch tactics for hightechnology products. Industrial Marketing Management, 25(2), 87-103. https://doi.org/10.1016/0019-8501(95)00037-2.

Begley, J., Berkeley, N., Donnelly, T. \& Jarvis, D. (2016). National policy-making and the promotion of electric vehicles. International Journal of Automotive Technology and Management, 16(3), 319-340. https://doi.org/10.1504/ ijatm.2016.10001648.

Bobeth, S. \& Matthies, E. (2016). Elektroautos: Top in Norwegen, flop in Deutschland?: Empfehlungen aus sicht der Umweltpsychologie. GAIA, 25(1), 38-48.

Cansino, J. M., Sánchez-Braza, A. \& Sanz-Díaz, T. (2018). Policy instruments to promote electro-mobility in the EU28: A comprehensive review. Sustainability, 10(7), 2507. https://doi.org/10.3390/su10072507.

Chovan, T. \& Straka, M. (2015). Layout and design of electromobile charging stations as urban elements. Acta Logistica, 2(4), 7-12.

Chung, C.W. \& Hsu, J.J. (2012). Application of Life Style Model to Analyze the Market of Department Stores. Journal of Service Science and Management, 5(3), 302-11.

Coppola, P. \& Arsenio, E. (2015). Driving societal changes towards an electromobility future. European Transport Research Review, 7(4), 1-2. https://doi.org/10.1007/s12544-015-0186-0.

EC-European Commission. (2011). Roadmap to a Single European Transport Area-Towards a competitive and resource efficient transport system. White Paper, Communication, 144. Retrieved July 18, 2019, from https://ec.europa.eu/transport/themes/strategies/2011_white_paper_en.

EC-European Council. (2019). European Council conclusions on the MFF, climate change, disinformation and hybrid threats, external relations, enlargement and the European Semester, 20 June 2019. Retrieved July 18, 2019, from https://www.consilium.europa.eu/en/press/pressreleases/2019/06/20/european-council-conclusions-20-june-2019/.

EP-European Parliament. (2007). REGULATION (EC) No 715/2007 OF THE EUROPEAN PARLIAMENT AND OF THE COUNCIL of 20 June 2007 on type approval of motor vehicles with respect to emissions from light passenger and commercial vehicles (Euro 5 and Euro 6 ) and on access to vehicle repair and maintenance information. Retrieved July 18, 2019, from https://eur-lex.europa.eu/LexUriServ/LexUriServ.do?uri=OJ:L:2007:171:0001:0016:EN:PDF.

Formánek, T. \& Tahal, R. (2016). Brand importance across product categories in the Czech Republic. Management \& Marketing, 11(1), 341-54.

Fox, J. \& Hong, J. (2009). Effect Displays in R for Multinomial and Proportional-Odds Logit Models: Extensions to the effects Package. Journal of Statistical Software, 32(1), 1-24.

Gebauer, F., Vilimek, R., Keinath, A. \& Carbon, C. (2016). Changing attitudes towards e-mobility by actively elaborating fast-charging technology. Technological Forecasting and Social Change, 106, 31-36. https://doi.org/10.1016/j.techfore.2016.02.006.

Gibbons, J.D. \& Chakraborti, S. (2003). Nonparametric Statistical Inference. $4^{\text {th }}$ edition. Berlin Heidelberg: CRC Press, 78-86. 
Greene, W.H. (2018). Econometric analysis. New York: Pearson.

Hastie, T., Tibshirani, R. and Friedman, J. (2001). The Elements of Statistical Learning: Data Mining, Inference, and Prediction. Springer New York Inc., New York, USA.

Kester, J., de Rubens, G.Z., Sovacool, B.K. \& Noel, L. (2019). Public perceptions of electric vehicles and vehicle-to-grid (V2G): Insights from a Nordic focus group study. Transportation Research Part D: Transport and Environment, 74, 277-293. https://doi.org/10.1016/j.trd.2019.08.006.

Kirsch, D.A. (2000). The Electric Vehicle and the Burden of History. New Brunswick, N.J.: Rutgers University Press. 153-162.

Messagie, M., Lebeau, K., Coosemans, T., Macharis, C. \& VanMierlo, J. (2013). Environmental and financial evaluation of passenger vehicle technologies in belgium. Sustainability, 5(12), 5020 5033. https://doi.org/10.3390/su5125020.

Papadopoulos, P., Skarvelis-Kazakos, S., Grau, I., Cipcigan, L. M. \& Jenkins, N. (2012). Electric vehicles' impact on british distribution networks. IET Electrical Systems in Transportation, 2(3), 91-102. https://doi.org/10.1049/iet-est.2011.0023.

Salah, K. \& Kama, N. (2016). Unification requirements of electric vehicle charging infrastructure. International Journal of Power Electronics and Drive Systems, 7(1), 246-253.

Tahal, R., Formánek, T. \& Mohelská, H. (2017). Loyalty Programs and Personal Data Sharing Preferences in the Czech Republic. E\&M. Economics and Management, 20(1), 87-99. https://doi.org/10.15240/tul/001/2017-1-013.

Wooldridge, J.M. (2010). Econometric Analysis of Cross Section and Panel Data. $2^{\text {nd }}$ edition. MIT Press, Cambridge.

Yan, Z., Lan, Y., Du, K., \& Yang, Z. (2017). Impacts of low-carbon innovation and its heterogeneous components on $\mathrm{CO}_{2}$ emissions. Sustainability, 9(4), 548. https://doi.org/10.3390/su9040548.

The research paper passed the review process. | Received: February 11, 2020; Revised: March 3, 2020; Accepted: March 6, 2020; Published: June 15, 2020. 